\title{
Toxic megacolon: the knee-elbow position relieves bowel distension
}

\author{
M Z Panos, M J Wood, P Asquith
}

\begin{abstract}
Toxic megacolon complicating inflammatory or infective colitis carries a high morbidity and mortality and surgical intervention is necessary in up to $80 \%$ of cases. ${ }^{12}$ Perforation complicates toxic megacolon in about $35 \%$ of cases. After perforation, the death rate nears $50 \%{ }^{3-5}$ Gaseous distension of the bowel causes considerable discomfort to the patient and increases transmural pressure. The latter is thought to cause a reduction in blood flow and may predispose to perforation. ${ }^{6}$ The use of instruments for colonic aspiration is discouraged, because of the high risk of perforation. ${ }^{6}$ The successful use of the knee-elbow position to relieve bowel distension in two patients with toxic megacolon is described.

(Gut 1993; 34: 1726-1727)
\end{abstract}

Department of Medicine, University of Birmingham Medical School,

Birmingham

M Z Panos

Department of Infectious Diseases, East Birmingham Hospital, Birmingham $M$ J Wood

Gastroenterology Unit, East Birmingham Hospital, Birmingham P Asquith

Correspondence to: Dr M Z Panos, Department of Medicine, University of Medirine, University of Queen Elizabeth Hospital, Birmingham B15 2TH.

Accepted for publication 27 April 1993

\section{Case report 1}

A 38 year old white man, presented with a two week history of febrile illness, rigors, and bloody diarrhoea (10-12 bowel actions daily), after returning from a visit to Thailand. Stool cultures had showed the presence of Shigella flexneri and Salmonella singapore. He had taken cophenotrope and loperamide in the week before admission. His temperature was $39 \cdot 4^{\circ} \mathrm{C}$, pulse 120 / $3.1 \mathrm{mmol} / \mathrm{l}$, urea $4.4 \mathrm{mmol} / \mathrm{l}$, albumin $29 \mathrm{~g} / \mathrm{l}$, orosomucoid $3.01 \mathrm{~g} / \mathrm{l}(\mathrm{n}<1 \cdot 20)$ haemoglobin $12.6 \mathrm{~g} / \mathrm{dl}$, white blood cells $9 \cdot 4 \times 10^{9}$, with a normal differential count. Stool microscopy and culture and blood cultures were negative. Shortly after admission abdominal distension and tenderness over the transverse colon was noted. A plain supine abdominal radiograph showed gaseous dilatation of the transverse colon min, serum sodium $137 \mathrm{mmol} / \mathrm{l}$, potassium

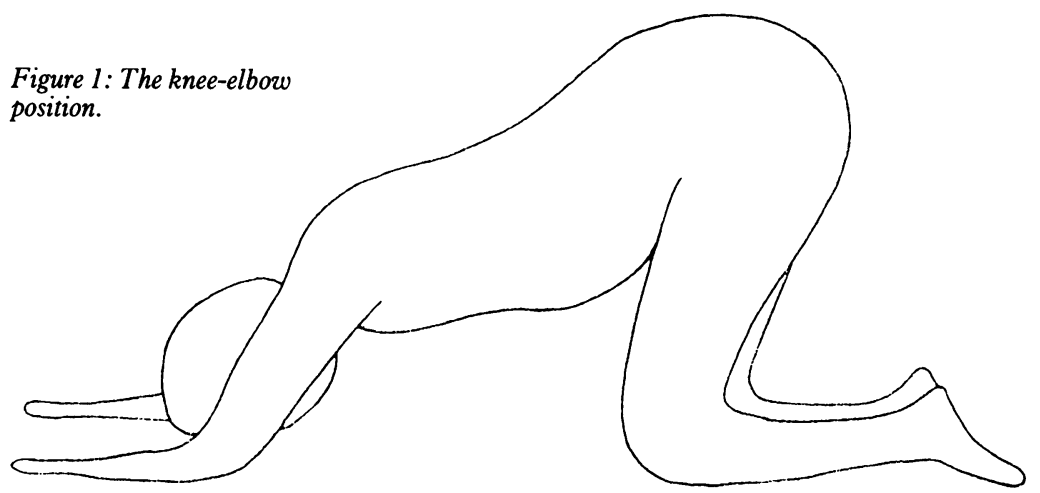

and small bowel. The diameter of the distal transverse colon was $10 \mathrm{~cm}$ and a diagnosis of toxic megacolon was made.

After 24 hours treatment with intravenous fluids, potassium supplements, cotrimoxazole and hydrocortisone, the patient's condition improved. His temperature was $37^{\circ} \mathrm{C}$, pulse $84 /$ $\mathrm{min}$, and serum potassium $3.8 \mathrm{mmol} / \mathrm{l}$. Although the number of bowel actions had decreased to 5/day, he complained of increasing abdominal discomfort. Abdominal girth measured $97 \mathrm{~cm}$ and the radiographic diameter of the distal transverse colon had increased to $11.5 \mathrm{~cm}$. Surgery was considered. A few hours later, while trying to find a comfortable posture, the patient adopted a kneeling position with his head lowermost (Fig 1). This resulted in passage of flatus, which continued for some minutes. He reported improvement of the abdominal discomfort and the manoeuvre was repeated a number of times with similar results. Twelve hours later, abdominal girth and the radiographic diameter of the distal transverse colon had decreased to 95 and $10 \mathrm{~cm}$ respectively, and there was a reduction in dilatation of small bowel loops. By 48 hours, the abdominal girth had decreased to $92 \mathrm{~cm}$. Over the next two weeks he made a slow clinical improvement and required blood transfusion and intravenous nutrition. He was discharged three weeks after admission, having recovered fully.

\section{Case report 2}

A 51 year old white man with a 28 year history of ulcerative colitis and ankylosing spondylitis had been receiving longterm treatment with sulphasalazine, until two years previously. He had a $\mathbf{1 0}$ day history of diarrhoea (10 bowel actions daily) without blood. He had received loperamide and ciprofloxacin without benefit. Two days before admission he noted abdominal distension and began to hiccup. His temperature was $38.8^{\circ} \mathrm{C}$, with a tachycardia of $120 / \mathrm{min}$. Arterial blood pressure was $140 / 90 \mathrm{~mm} \mathrm{Hg}$ with no postural drop. The abdomen was distended and the outline of the transverse colon clearly visible. Abdominal girth measured $116 \mathrm{~cm}$. Stool microscopy and culture, and blood cultures were negative. Serum sodium was $136 \mathrm{mmol} / \mathrm{l}$, potassium $3.7 \mathrm{mmol} / 1$, urea $2.5 \mathrm{mmol} / \mathrm{l}$, albumin 22 $\mathrm{g} / \mathrm{l}$, orosomucoid $1.91 \mathrm{~g} / \mathrm{l}$, haemoglobin 14.6 $\mathrm{g} / \mathrm{dl}$, white blood cell count $17 \cdot 4 \times 10^{9}$ and platelets $313 \times 10^{9}$. A plain abdominal radiograph 


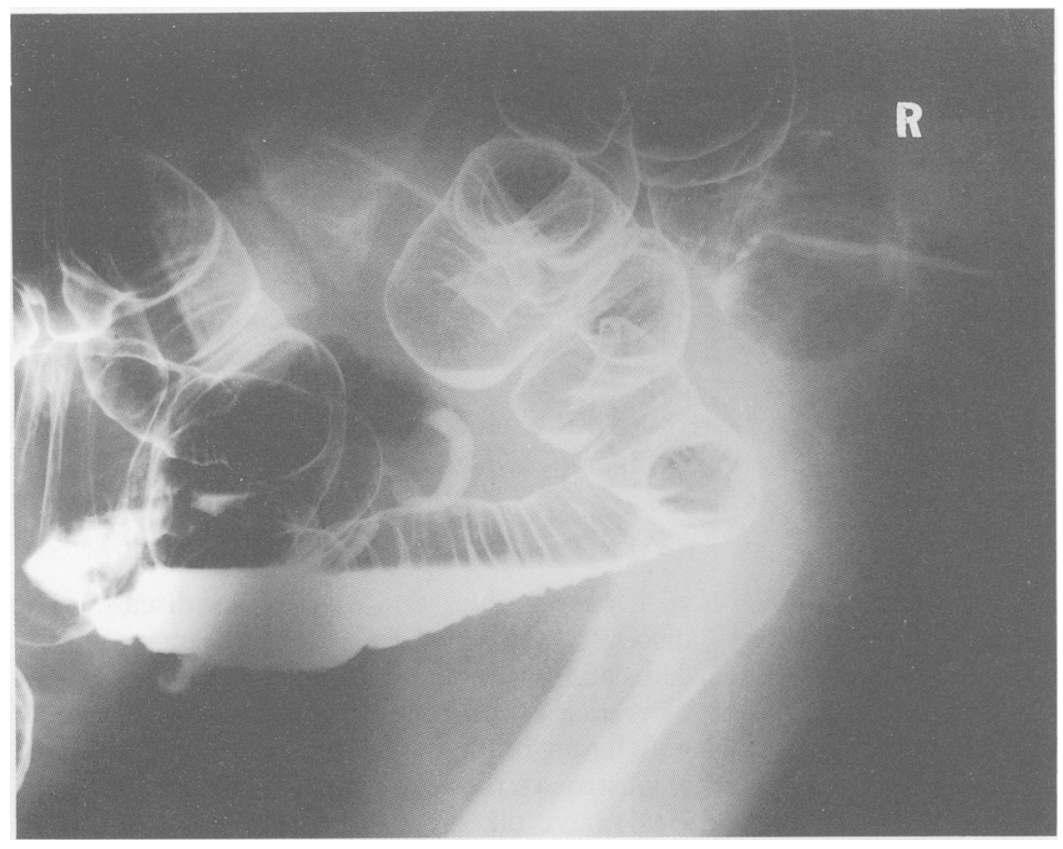

Figure 2: Double contrast barium enema. Lateral 'through-view' of the abdomen with patient in the knee-elbow position shows accumulation of fluid in dependent bowel loops and gas in the distal sigmoid colon and rectum $(R)$.

showed gaseous distension of the transverse colon (distal transverse colon diameter $10 \mathrm{~cm}$ ) with mucosal oedema.

A diagnosis of toxic megacolon was made and the patient was given intravenous fluids, potassium supplements, intravenous metronidazole, cefuroxime, and hydrocortisone. After 24 hours, his temperature was $37^{\circ} \mathrm{C}$ and the pulse rate $90 /$ min. He complained of increasing abdominal discomfort. Abdominal girth had not changed but a repeat plain abdominal film showed the radiographic diameter of the distal transverse colon had increased to $11.5 \mathrm{~cm}$. In addition, there was distension of the caecum $(9.5 \mathrm{~cm})$ and descending colon $(7 \mathrm{~cm})$. On the basis of our findings from case 1 , the patient was advised to adopt the knee-elbow position for five minutes every half hour. Assumption of the position, almost invariably resulted in spontaneous passage of wind, often started by a gentle cough. Abdominal discomfort lessened and abdominal girth decreased steadily to $108 \mathrm{~cm}$ within 12 hours. Improvement was reflected in the radiological findings. At 12 hours, the diameter of the distal transverse colon was $7 \mathrm{~cm}$, caecum $4 \mathrm{~cm}$, and descending colon $2.5 \mathrm{~cm}$. At 48 hours the diameter of the distal transverse colon was $2.0 \mathrm{~cm}$. He made steady improvement and was discharged 12 days after admission.

\section{Discussion}

In both cases established criteria for the diagnosis of toxic megacolon were fulfilled. ${ }^{7}$ Deflation of the colon (recorded by girth and radiological measurements) with relief of symptoms was achieved by a simple, safe postural manoeuvre. We propose that in the knee-elbow position, mobile bowel loops shift to a dependent position, while the rectum remains uppermost. Fluid shifts to dependent bowel loops and allows gas to rise to the rectum. We obtained supportive evidence for this explanation from a double contrast barium enema investigation of a patient complaining of changed bowel habit. A lateral 'through-view' abdominal radiograph, taken with the patient in the knee-elbow position, confirmed fluid accumulation in dependent bowel loops and shift of gas to the sigmoid colon and rectum (Fig 2).

Although the knee-elbow position has been recommended to facilitate digital examination of the rectum ${ }^{8}$ and sigmoidoscopic decompression of sigmoid volvulus, ${ }^{9}$ we are not aware of any previous reports of its use for decompression of the bowel in toxic megacolon. We advocate the use of the knee-elbow position in all cases of toxic megacolon to deflate the bowel and achieve relief of symptoms. In addition, it is possible that colonic decompression may reduce the chance of perforation and improve blood flow to the bowel wall. ${ }^{6}$ Persistent colonic dilatation may constitute an indication for surgical intervention. ${ }^{6-10}$ Therefore, it is possible that relief of gaseous distension may have some influence on a surgical decision. A prospective assessment of the possible influence of bowel decompression on outcome, may be appropriate.

1 Greenstein AJ, Sachar DB, Gibas A, Scrog T, Heimann T, Janowitz $\mathrm{D}$, et al. Outcome of toxic dilatation in ulcerative and Crohn's colitis. F Clin Gastroenterol 1985; 7: 137-41.

2 Grant CS, Dozois RR. Toxic megacolon: ultimate fate of patients after successful medical management. Am $\mathcal{F}$ Surg 1984; 147: 106-10.

3 Muncroft TJ, Warren PM, Asquith PA, Montgomery RD, Sokhi GS. Toxic megacolon in ulcerative colitis: a continuSokhi GS. Toxic megacolon in ulcerative colitis:
ing challenge. Postgrad Med $\mathcal{f} 1981 ; 57: 223-7$.

4 Flatmark A, Fretheim B, Gione E. Early colectomy in severe ulcerative colitis. Scand f Gastroenterol 1975; 10: 427-31.

5 Cello JP, Scneiderman DJ. Ulcerative colitis. In: Sleisenge HM, Fordtran JS, eds. Gastrointestinal disease. 4th Ed. Philadelphia: WB Saunders, 1989: 1435-77.

6 Norland CC, Kirsner JB. Toxic dilatation of colon (toxic megacolon): etiology, treatment and prognosis in 42 patients. Medicine $1969 ; 48: 229-50$.

7 Jalan KN, Sircus W, Card WI, Falconer CWA, Bruce J. An experience of ulcerative colitis: Toxic dilatation in 55 cases. experience of ulcerative colitis: T.
Gastroenterology 1969; 57: 68-82.

8 Hamilton Bailey. Physical signs in clinical surgery. 11th Ed. Bristol: J Wright, 1949: 229.

9 Dudley HAF, ed. Hamilton Bailey's emergency surgery. 10th Ed. Bristol: J Wright, 1977: 494.

10 Odyniec NA, Judd ES, Sauer WG. Toxic megacolon. Significant improvement in surgical management. Arch Surg 1967; 94: 638-43. 